\title{
Improving the Song Notation Reading Comprehension and Skill of Prospective Elementary School Teachers: An Action Research Study in Indonesia
}

\author{
J. Julia ${ }^{1, *}$, I. Isrokatun ${ }^{1}$, Hikmat Pramajati ${ }^{2}$, Nunung Siti Sukaesih ${ }^{2}$, Iis Aisyah ${ }^{2}$ \\ ${ }^{1}$ Prodi PGSD Sumedang, Universitas Pendidikan Indonesia, Indonesia \\ ${ }^{2}$ Prodi Keperawatan Sumedang, Universitas Pendidikan Indonesia, Indonesia
}

Received August 10, 2019; Revised September 4, 2019; Accepted September 16, 2019

Copyright $\bigcirc 2019$ by authors, all rights reserved. Authors agree that this article remains permanently open access under the terms of the Creative Commons Attribution License 4.0 International License

\begin{abstract}
Students in Indonesian elementary school teacher education programs tend to have weaker song notation reading skill. To improve their skill in reading and understanding song notations, critical and reflective steps are necessary. Therefore, this research aims at improving the students' skills in reading and understanding song notations, which is necessary for their future teaching profession. This research was conducted using an action research design, manifested by planning and implementing seven critical-reflective action steps. The participants were 44 undergraduate students in an elementary school teacher education program in a university in West Java, Indonesia. The research found that the prospective elementary school teachers were not accustomed to reading the symbols in song notations. Therefore, their musical literacy was low. However, this research found that their song notation reading comprehension and skill could be improved by implementing several critical-reflective action steps. Additionally, the reports from this research illustrated the results of collaborative teamwork in developing and finding solutions in each of the learning steps.
\end{abstract}

Keywords Musical Literacy, Notation Reading Skill, Song Analysis, Song Notation, Students' Comprehension

\section{Introduction}

Elementary school teachers in Indonesia have an obligation to teach songs to students from grade one to grade six (six years), and the songs in textbooks are written in song notations with note symbols. Therefore, the teachers are expected to be able to read the song notations to know the song melodies as the learning materials. Additionally, besides teaching the lyrics and melodies of the songs, the teachers are also obliged to teach using solmization. This means that, in addition to comprehending song notations, the teachers need to be able to transcribe the note symbols into solmization. These obligations are explicitly stated in the curriculum on music education for elementary school. As a consequence, if teachers are unable to read song notations, the materials will not be delivered well to the students. Even worse, if music classes are not implemented well, the students will not be able to develop and train their vocal pitch and achieve musical or aesthetic experiences (Elliott, 1995). Furthermore, studies show that vocal accuracy development is significantly affected by the human voice as the model (Hermanson, 1972; Julia, Hakim, \& Fadlilah, 2019; D. Persellin, Smith, Klein, \& Taguiam, 2002; D. C. Persellin, 2006; Sims, Moore, \& Kuhn, 1982; Yarbrough, Green, Benson, \& Bowers, 1991).

Several previous studies conducted as an effort to develop musical literacy have discovered important findings with regards to musical literacy. Lee et al. (2011) developed musical literacy using technology by constructing a two-wheeled robot that functions by reading music and sing songs with a synthesized voice autonomously. Their research found that the recognition accuracy was over $98 \%$. Second, Penttinen, Huovinen, and Ylitalo (2015) conducted a study on the eye movements of adult music students in temporally controlled performances of a children's song. In this study, the participants read and performed two versions of a simple melody, including the original version and melodically altered versions, in a given tempo. During the process, their eye movements were recorded. An analysis was also conducted for errorless trials to explore the adjustments of visual processing in successful performances. The results of the study manifested the flexibility and limitations of the visual processing mechanisms in the reading process of 
temporally controlled music. Third, Puurtinen (2018) conducted a study by developing a method to read song notations called "looking ahead". The study used data that has been collected for 10 years. It was conducted due to one of the key characteristics of music reading, which is that the gaze of the music reader moves a little bit ahead of the current point of performance. The study revealed that there are progress and setbacks in eye-tracking studies on reading music.

From observations in different school throughout 2018, it has been found that the majority of elementary school teachers in West Java, Indonesia, did not have satisfactory ability to read song notations. They could not comprehend how to read the notations in various key signature and time signature changes. Although some teachers could read song notations, they could not do it for the song notations in the form of note symbols, only those in the form of numerical symbols - that are the note symbols that have been transcribed into the number of one through seven. In addition, observations were also conducted to undergraduate students in an elementary school teacher education program in a university in West Java. Upon testing of song notations reading and analysis, it was found that only $10 \%$ of 120 students could read and comprehend song notations. Moreover, they could only read the song notations in the $\mathrm{C}$ major position; when the key signature and time signature were changed, they could not comprehend the changes. From these findings, it can be said that there are serious problems in this area that require to be solved. For instance, when teachers and prospective teachers do not have the ability to read song notations, it can be assured that they will face obstacles in comprehending and teaching songs provided in the song textbook.

Departing from this concern, this research was conducted with the aim of improving the song notation reading comprehension and skill of prospective elementary school teachers. The research posed a number of questions based on the aforementioned issues, including: (1) Why are prospective elementary school teachers unable to read song notations?; (2) Are prospective elementary school teachers aware of the importance of song notation reading comprehension and skill?; (3) Do prospective elementary school teachers know how they can improve their song notation reading comprehension and skill?; and (4) Can a set of steps to read song notations improve the prospective elementary school teachers' song notation reading comprehension and skill?. Based on this set of research questions, an action research was conducted.

\section{Theoretical Framework}

In some literature, song notation reading is described as music reading skill and is a part of musical literacy. Music reading is an intricate process that involves at least two distinct skills: reading and mechanical skills (Wolf, 1976). From a cognitive perspective, a number of simultaneous processes are needed in music reading, such as visual information, motor responses, and visual-motor integration (H. Gudmundsdottir, 2007). According to studies, high-level music-reading achievement at a high level is determined by information processing speed and psychomotor speed (Kopiez, Weihs, Ligges, \& Lee, 2006). Therefore, it can be concluded that the decoding ability and the motor response are necessary for music reading, but their integration may be the key to a successful execution (H. R. Gudmundsdottir, 2010).

The staff notation reading or the musical symbol decoding is a multiple task in itself. Sloboda believes that music reading is a construct of processes in music perception (Sloboda, 1976, 1978, 1984). Moreover, according to studies on perception, pitch information and timing information are processed separately (Palmer \& Krumhansl, 1987) (Palmer \& Krumhansl, 1987). Because of this, it can be said that pitch and timing information is coded separately in western staff notation. Furthermore, studies have confirmed that pitch and timing in the context of music reading are perceived separately (Schön \& Besson, 2002; Waters \& Underwood, 1999). In addition, studies on musicians with brain injuries have found more evidences of the separate processing of pitch and timing. One study describes how a professional musician was able to read only pitches but not the rhythm in musical notation after suffering brain damage (Fasanaro, Spitaleri, Valiani, \& Grossi, 1990). Therefore, the decoding in music reading entails the separate processes of pitch reading and timing reading regardless of the fact that these two must be integrated in the motor output (H. R. Gudmundsdottir, 2010).

The benefits of music literacy for musical and academic growth have been explored in previous studies (Burton, 2017; Elkoshi, 2007; Hultberg, 2007; Ilomaki, 2007; Long, 2007; Rusinek, 2007). Ilomaki (2007) conducted a study on the conceptions and understanding of notation among pianists in music conservatories and discovered that the promotion of professional development in music required a conception of music literacy. Then, a study conducted by Rusinek (2007) investigated "good teaching practice" approach characteristics in compulsory secondary music education in Spain, which included an efficient sequencing of rhythmic reading and decoding of melodic notation for performing. Moreover, a study conducted by Long (2007) identified the effect of a rhythm-based music intervention involving small groups of children stamping, clapping and chanting while reading music notation "in time", which was that it increased the reading comprehension of the pupils in the music course. Finally, a study conducted by Hultberg (2007) analyzed the performance preparation of professional musicians who explored the score to develop their ideas of the music and found that music notation functioned as a "psychological tool for intellectual 
development".

Conversely, some researchers denied notation as an educational goal and expressed concern regarding its possible damage to students (Bamberger, 1995; Cook, 1990; Elkoshi, 2007). In her study, Bamberger (1995) found that, as children gained facility in reading and writing staff notation, they seemed to simultaneously lose their sensitivity to the figural, "musical sense" of rhythm. She calls this the wipe-out phenomenon and criticizes traditional school music that promotes formal education at the expense of intuitive understanding, such that some forms of creative expression may effectively be suppressed. She suggests that intuitive understanding is important in musical cognition that teachers must not be discouraged from training in formal skills (Hargreaves, 1992).

In contrast with previous studies, this research aims at prospective elementary school teachers that have the obligation to teach songs to their students but are yet to have good comprehension regarding song notations, especially in reading the song notations. This research was conducted using an action research design with the consideration that the problems faced by the prospective elementary school teachers need to be solved by certain interventions or problem-solving actions in each learning step. Action research design has the proper methodology to improve the prospective teachers' comprehensions and teaching practices to improve musical literacy through sustainable planning, implementation, and reflection.

\section{Methods}

\subsection{Research Design}

This research was conducted using an action research design, which is currently a popular design used in pedagogic research (Edwards-Groves \& Kemmis, 2016; Somekh \& Zeichner, 2009; Supriyadi \& Julia, 2019; Zuber-Skerritt, 2018). The most distinctive aspect of this design is that improvements can be made by the problem solver (Bozkuş \& Bayrak, 2019; Greenwood \& Levin, 2006). In practice, action research attempts to intensively find solutions to problems (Creswell, 2015). This is in line with the problem of prospective elementary school teachers in reading and comprehending song notation, which requires intensive solutions in each learning process, considering that reading song notation is a part of the music-reading skill that needs to be practiced intensively. Additionally, the action research design was also used in this research to understand self-practice so that it allows for improvements in every action (Kemmis \& McTaggart, 2005; Kemmis, McTaggart, \& Nixon, 2014; McTaggart, 1994). Through action research, planning, implementation, and reflection on every step could take place (McTaggart, 1996).

\subsection{Research Procedure}

This research was conducted in three main stages, which include seven sub-stages in the actions. The first stage included a survey, an initial test, and an initial analysis of the skill and perception of the participants regarding song notation reading. The second stage included the implementation of actions in accordance with the planning, followed by a reflection in each action. This stage resulted in seven critical-reflective steps as an effort to make the participants understand song notations as well as analyzing and reading the song notations. The third stage was a final test aimed at identifying the participants' changes in song notation reading comprehension and skill. Surveys were conducted through Google Docs using the Likert scale and the Gutman scale. Google Docs has become an advantageous survey tool and is easy to use (Brigham, 2014; Chiu, Cheng, \& Wu, 2016; Lin, Chang, Hou, \& Wu, 2016; Travis, 2010). Furthermore, the participants were also given open questions. Meanwhile, the knowledge test was done using Quiz in Google Docs, and the notation reading skill test was conducted directly and individually while being video recorded. Additionally, observations were conducted in each learning step.

\subsection{Collaborative Aspect}

Collaboration is an important aspect of action research (Bruce, Flynn, \& Stagg-Peterson, 2011; Creswell, 2015; Ferguson-Patrick, 2007; Jaipal \& Figg, 2011; Leeman, van Koeven, \& Schaafsma, 2018; Somekh, 2010). During the process, this research involved some parties who care about music education. The teachers that participated in music teaching training activities expressed that they found it difficult to learn song notation. They did not get adequate lessons of song notation reading while attending formal education. Then, they suggested that prospective elementary school teachers should be given additional lessons on song notation reading, and a teacher was willing to help carry out this project. This problem should be addressed by involving other parties in a collaborative team. According to Heil (2005), forming a collaborative team can be done by exposing the project and seeing who is interested. To follow this method, this problem was exposed to the researcher's colleagues and some people were interested in participating in the project. Together with the collaborative team, the researcher developed what needs to be prepared to carry out the project. Then, it was agreed upon to compile the research instruments and plan the learning steps. In addition, it was also agreed that the outcome of this project was that participants could play song melodies by reading notations, using either musical instruments, music applications, or their own vocals. In the research process, participants who already had the ability to read song notations were also involved in peer tutoring activities. The peer tutoring activities were increasingly 
developing with the increasing number of participants who began to become more skilled and attempted to share their skills with other participants.

\subsection{Research Site and Subject}

This research was conducted at an elementary school teacher education program in one of the leading universities in the province of West Java, Indonesia. Many students in this program are from outside the city. The research subjects involved were 44 students from the second semester with a composition of 42 (95.5\%) women and two $(4.5 \%)$ men. In Indonesia, elementary school teacher education programs are more in demand by women. Their age ranges from 18-20 years old. A total of 11 (25\%) students came from Sumedang city, 6 (13.6\%) students came from Bandung, 5 (11.4\%) students came from Cirebon, $6(13.6 \%)$ students came from Majalengka, 3 $(6.8 \%)$ students came from Indramayu, $3(6.8 \%)$ students came from Bogor, 1 (2.3\%) student came from Kuningan, 5 (11.4\%) students came from other regions in West Java, and $1(2.3 \%)$ student came from other areas outside West Java. In terms of motivation, $11(25 \%)$ students had very high motivation to become vocal instructors, $13(29.5 \%)$ students had high motivation to become vocal teachers, 12 $(27.3 \%)$ students had moderate motivation to become vocal teachers, and $8(18.2 \%)$ students had low motivation to become vocal teachers. All of the students agreed to take part in this research and gave their permission to use their information as research data.

\section{Results}

\subsection{Pre-Action Analysis}

The initial analysis was carried out to identify the participants' knowledge of song notations by giving a survey. The survey results in Table 1 show that of all the participants $(n=44,100 \%)$, the majority of the participants claimed to have learned about song notations $(n=36$, $81.8 \%$ ), were able to understand and describe song notations $(n=24,54.5 \%)$, knew the note values in song notations ( $n=30,68.2 \%)$, knew the key signature of song notations $(n=30,68.2 \%)$, and can read song notations ( $n=$ $29,65.9 \%)$. In addition, the majority of the participants claimed not to comprehend the terms listed in song notations $(n=23,52.3 \%)$ and did not know the tone interval in song notations $(n=30,68.2 \%)$. This data shows that, of the seven aspects identified, the participants acknowledged five aspects to be in a positive condition (good), and two aspects to still be in a negative (bad) condition.

Statements from the participants who showed more positivity in understanding song notations need to be proven by directly reading and analyzing song notations. The participants were tested with two types of song notations to analyze, namely notation in $\mathrm{C}$ major tonality with $4 / 4$ rhythm and D major tonality with $6 / 8$ rhythm (two sharp). The test results showed that the majority of the participants knew the $\mathrm{C}$ major song base tone $(n=36$, $86.4 \%$ ) and knew the highest and lowest tones in the song melody in $\mathrm{C}$ major $(n=25,56.8 \%)$, the majority of the participants did not know the note values $(n=41,93.19 \%)$, and all of the participants did not know the interval of tones from one note to another $(n=44,100 \%)$. In addition, no participant was able to answer all questions related to the song notation in $\mathrm{D}$ major tonality correctly. The participants did not know that sharp or flat signs as key signatures cause changes in the solmization position. They also did not know that the difference in numbers in the time signature causes changes in the note values. When the participants were tested to read song notations, all of them could not read the note symbols properly, especially for the notation outside the $\mathrm{C}$ major tonality. When asked, "Why did you say you could read song notation?" some participants answered that they could read the number notation, not the note symbols. This answer provided an understanding that the habit of reading song notations in the form of number notations in Indonesia might cause the participants to be unfamiliar with note symbols.

Table 1. Participants' initial knowledge of song notations

\begin{tabular}{|l|c|c|}
\hline Initial Knowledge of Song Notations & Yes & No \\
\hline Have you ever learned about song notations? & 36 & 8 \\
\hline Can you comprehend and describe song notations? & 24 & 20 \\
\hline $\begin{array}{l}\text { Do you comprehend the terms listed in song } \\
\text { notations? }\end{array}$ & 21 & 23 \\
\hline Do you know the values of notes in song notations? & 30 & 14 \\
\hline Do you know the tone interval in song notations? & 14 & 30 \\
\hline Do you know the key signature of song notations? & 30 & 14 \\
\hline Can you read song notations? & 29 & 16 \\
\hline
\end{tabular}

Considering that the majority of the participants were unable to read and comprehend song notation in the form of note symbols, follow-up questions were given to the participants. The questions were focused on the participants' knowledge about the condition of actual music teachers at school. It was considered important to ask in order to know the participants' potential preparations when they notice that their job might require vocal lessons equipped with song notation reading skill. From Table 2, it can be identified that the majority of the participants knew that vocal teaching materials in elementary schools use song notations $(n=25,56.8 \%)$, and they were also aware of the impact of a vocal teacher who taught vocals without being able to read song notations $(n=29,65.9 \%)$. Based on this data, there were still many participants who had to be made aware of the importance of mastering notation reading skills in teaching at school. 
Table 2. Participants' knowledge of the use of song notations

\begin{tabular}{|c|c|c|}
\hline The Use of Song Notations in Vocal Lessons & Yes & No \\
\hline Do you know that vocal teaching materials in elementary school use song notations? & 25 & 19 \\
\hline Do you know the impact of a vocal teacher who teaches vocals without being able to read song notations? & 29 & 15 \\
\hline
\end{tabular}

Table 3. Participants' perception of reading song notations

\begin{tabular}{|l|c|c|c|c|c|}
\hline Statements About Song Notation Reading Skill & $\begin{array}{c}\text { Strongly } \\
\text { Disagree }\end{array}$ & Disagree & $\begin{array}{c}\text { Rather } \\
\text { Agree }\end{array}$ & $\begin{array}{c}\text { Agree } \\
\text { An elementary school teacher must be able to read song notations. }\end{array}$ & $\begin{array}{c}\text { Strongly } \\
\text { Agree }\end{array}$ \\
\hline Songs can be taught properly when the teacher can read song notations. & & 1 & 12 & 11 & 19 \\
\hline $\begin{array}{l}\text { Prospective elementary school teachers require lessons on how to read } \\
\text { and comprehend song notations. }\end{array}$ & & 2 & 6 & 11 & 24 \\
\hline $\begin{array}{l}\text { Prospective elementary school teachers do not get the proper education } \\
\text { on song notations for since their previous education. }\end{array}$ & 7 & 7 & 18 & 5 & 7 \\
\hline
\end{tabular}

The aforementioned participants' positive statements that contradict their actual skill in reading and understanding song notations required a further analysis by investigating their motivation to grow. To do this, the participants were required to participate in a survey, where they rated statements on a scale of 1-5 (Strongly DisagreeStrongly Agree). Their perceptions can provide an overview to develop the right steps to improve their comprehension and skill in reading song notations. The results of the survey are presented in Table 3 .

From Table 3, it can be identified that the majority of participants had strong opinions by agreeing $(n=11,25 \%)$ and strongly agreeing $(n=19,43.2 \%)$ with the statement that teachers must be able to read song notations. The majority of participants also gave positive opinions by agreeing $(n=8,18.2 \%)$ and strongly agreeing $(n=24$, $54.5 \%$ ) with the statement that songs can be taught properly if the teacher can read song notations. Their statement also shows strong motivation by giving agreeing ( $n=16,36.4 \%)$ and strongly agreeing $(n=20,45.5 \%)$ with the statement that prospective teachers must be taught how to read and understand song notations. Meanwhile, the majority of participants disagreed that they did not get proper education on song notations from their previous education ( $n=18,40.9 \%)$. The participants' statements illustrate that prospective elementary school teachers needed the song notation reading skill, so it is important to teach them how to master the skill. Their previous education was considered to have provided proper knowledge even though they did not understand notations let alone read them. Therefore, it was necessary to arrange some activities to help the students develop their skills in reading and comprehending song notations.

\subsection{Action Units of Building Understanding of Song Notation}

Based on the crucial aspects that must be comprehended by the participants in reading song notations that were found in the pre-action survey, seven critical stages of action were developed, which must be applied to the participants in addition to small treatments at each step. Reflections in each step were carried out continuously. Throughout the journey, the development of the participants' skills was evaluated to determine the actions that respond to their needs. Below are the seven stages to improve the song notation reading comprehension and skill of prospective elementary school teachers.

\section{Step 1: Getting Attention and Building Students' Motivation}

In this step, the importance of reading song notations in teaching was highlighted for the participants using many song examples for elementary school children in the form of song notations, including examples from textbooks published by the government. In addition, it was also shown that the songs used a variety of key signatures and time signatures, so participants had to understand any changes or differences in the song notations. Some examples of song notations were taken from children's song provider website, such as www.singing-bell.com. The participants were also assigned to look at basic musical competencies in the elementary school curriculum. They became more aware that the curriculum requires teachers to teach songs by singing melodies and lyrics, solmization, and different rhythms.

\section{Step 2: Introducing the Functions of Song Notations in Vocal Teaching}

The pre-action survey results showed that $32(72.7 \%)$ participants claimed to know the functions of song notations in vocal teaching. Meanwhile, 14 (31.8\%) participants did not know it. When asked, "What do you think are the functions of song notations?" A participant answered, "To know how to sing the song properly and correctly." Other participants answered, "So that each tone is sung correctly and in accordance with the song's notation." There were also participants who answered, "Song notation makes it easy for us to read or sing a song properly and correctly." The answers from the participants illustrates that some of them actually already knew some of the functions of song notations in vocal teaching. However, 
a number of important things were missing. Therefore, the participants were given an explanation that, in vocal teaching, song notation can function as a basic ingredient for applying song melodies, knowing song tonality, knowing song rhythms, and being a reminder of song melodies. In other words, a teacher who is about to teach a new song can learn the song by looking at the song notation. Similarly, the teacher who forgets the melody of a particular song can recall it by reading the song notation. In addition, they will not sing the wrong melody if they teach vocal by reading song notations. In addition, the participants were given concrete examples depicting elementary school students in Indonesia who sang patriotic songs with wrong melodies because they were not taught by the teacher by reading song notations, but orally, or because the teacher heard incorrect examples and then taught the students.

\section{Step 3: Analyzing Song Notation}

The results of the pre-action song notation analysis test showed that the participants could not understand the changes and consequences of the key signature and time signature. They also have not been able to identify tone intervals in various tonalities, including determining the highest and lowest tones of a song with a change in the position of the solmization due to changing tonality. At this stage, the participants were asked to analyze a simple song notation titled "Kumbaya" (D major tonality, 3/4 rhythm), which was taken from www.singing-bell.com/kumbaya-mp3-lyrics-score/. To address the analysis needs, the participants were guided with questions about various aspects seen in the notation. For example, "What is the meaning of 3/4?" "What is the name of the clef used?" "What is the function of the key?" "What notes are used?" "What is the tonality?" "What is the highest and lowest tone (melody range)?" "What is the rhythmic pattern?" The results of the analysis showed that the majority of the participants knew that the number $3 / 4$ was the time signature, but all of the participants did not know the meaning of the number three on top and the number four on the bottom. The participants knew that the key used was G, but they did not know the function of using the key. They also asked what the difference was with the F key. The participants did not know the names of the correct notes used in song notation; they generally referred to the notes as half, quarter, or one tap note. The participants did not know what the tonality of the song was, and they did not know what the two function marks were in the notation. The participants also did not automatically know what the highest and lowest notes were in the song. The same is true for counting tone intervals, because they did not know how the tone changes with the sharp sign, they did not know how to calculate the tone interval. These findings implied that the participants did not have sufficient comprehension on the development of basic materials of music elements. However, through the activity of analyzing song notation, the participants became more aware that their knowledge in the basic theory of music was still inadequate.

\section{Step 4: Increasing Knowledge about Music Elements}

The participants needed to learn more about the basic theory of music. Therefore, they were given lessons about it in accordance with the results of the song notation analysis done previously. The participants were given an explanation of the number $3 / 4$ in the notation (time signature or meter); the number three on top is the number of beats in each bar and the number four on the bottom is a note that is used as a benchmark in each beat, taken from note $1 / 4$. This explanation was developed further because apparently the participants did not know for sure the names of the notes, so they needed an explanation of the names of the notes, such as full note, $1 / 2$ note, $1 / 4$ note, $1 / 8$ note, $1 / 16$ note, and 1/32 note. In addition, there was also a demonstration of the types of notes to see the difference in sound length (value) in the $3 / 4$ time signature using a music notation software, Sibelius. The participants were also given examples of changes to read the note when the time signature was changed to $6 / 8$. The participants realized that the way you read the notes changes according to the time signature used. At the time, they thought that the note used as a benchmark in each beat was only $1 / 4$. Then, the next explanation was about the tonality of songs that are characterized by sharp or flat signs in song notation. Following this was an example that the sequence of solmization can change based on sharp or flat signs. Through these explanations, the participants realized that the position of solmization was relative because it followed the tonality used, while the tone sequences such as C-D-E-F-G-A-B-C' were absolute because they always remained in the same line and space in the music staff, and only changed following the clef used. By knowing the change in position of solmization, the participants also understood how to measure tone intervals, including determining the highest or lowest tone in a song. However, it was found that they could not read the rhythmic pattern accurately. To address this, the materials of various rhythmic patterns were prepared to be used as their teaching materials.

\section{Step 5: Reading the Rhythmic Pattern}

The participants were given simple rhythmic patterns to read. Then, they were shown a demonstration of how to read the rhythm. In addition to the oral demonstration, a demonstration using the music notation software, Sibelius, was also given. Examples of rhythmic patterns were also given in different time signatures, such as $2 / 4,3 / 4,4 / 4$, and $6 / 8$. By learning to read this rhythmic pattern, it was implied that the most participants could read different notes and time signature values. However, some participants had difficulty doing the reading. The problem here was that they had difficulty reading the notes when the notes were combined with $1 / 8$ note and $1 / 16$ note. This problem was identified when the participants were asked to maintain a 
stable tempo and reading the note at the same time. They recently noticed that reading notation must be bound by the tempo. In addition, they were sometimes not aware of the length of the notes that must be sounded; sometimes the 1/4 note was read in two taps. They were constantly reminded of this problem by doing exercises of reading various simple rhythmic patterns. The challenge was that some participants found it difficult to read a notation coupled with a break, or read a note in an arsenic position. To address this, they were invited to practice repeatedly to hone their musical sensitivity in order to be able to read the rhythmic patterns appropriately.

\section{Step 6: Playing Song Melodies Using Piano Application}

When the majority of participants could to read the rhythmic pattern correctly, they proceeded to the final stage of learning to read song notations by playing a series of melodic songs using both vocals and musical instruments. When practiced with vocals, the majority of the participants' vocals were not good enough to produce inappropriate vocal pitches. Therefore, the participants were instead assigned to read song notations and play the notes using the piano. However, because there was only one keyboard in the classroom, the participants were assigned to learn to read song notations using the piano application on their cellphones. The application used was "Piano Perfect" from the Google Play Store. All participants installed the piano application on their mobile phones, but another problem arose; they were confused with the position of the notes when they started reading. They did not know what to do in the position of the notes listed on the lines and spaces in the music staff on the piano application. They did not know the $\mathrm{C} 1-\mathrm{C} 7$ position on the piano and the position in the music staff. Therefore, a further explanation was provided by projecting Virtual Piano (PC 73 Virtual Piano Keyboard) on a screen to explain the position of $\mathrm{C} 1-\mathrm{C} 7$ and show where the notes are in the song notation. The explanation was given by exemplifying that the notes in the position of the first auxiliary line (on the $\mathrm{G}$ key, C majority tonality) below the first line were C4 keys. Slowly, the participants started to understand the synchronization between the position of the piano keys and notes on the song notation. The participants were given two children's songs as material for reading and memorizing the position of the piano keys. They were also assigned to look for other children's song melodies to be played as reading practice material.

\subsection{Post-action Analysis}

The participants were tested again after going through the action steps. They were presented with a song notation to analyze and then answer several questions based on the results of their analysis. Important aspects that were explored from the participants as a reflection of their understanding of song notation include knowledge of key signatures, time signatures, melody ranges, and tone intervals. The test results is presented in Table 4 .

Table 4. Final song notation analysis test results

\begin{tabular}{|c|c|c|c|c|}
\hline \multirow{2}{*}{$\begin{array}{c}\text { Song Notation Analysis } \\
\text { Test }\end{array}$} & \multicolumn{2}{|c|}{$\begin{array}{c}\text { Answered } \\
\text { Incorrectly }\end{array}$} & \multicolumn{2}{c|}{$\begin{array}{c}\text { Answered } \\
\text { Correctly }\end{array}$} \\
\cline { 2 - 5 } & Total & $\%$ & Total & $\%$ \\
\hline $\begin{array}{c}\text { Determining key } \\
\text { signature }\end{array}$ & 0 & 0.00 & 44 & 100 \\
\hline $\begin{array}{c}\text { Determining time } \\
\text { signature }\end{array}$ & 5 & 11.37 & 39 & 88.63 \\
\hline $\begin{array}{c}\text { Determining the lowest } \\
\text { and highest tones }\end{array}$ & 8 & 18.19 & 36 & 81.81 \\
\hline $\begin{array}{c}\text { Determining tone } \\
\text { intervals }\end{array}$ & 19 & 43.19 & 25 & 56.81 \\
\hline
\end{tabular}

Based on Table 4, it can be identified that all participants have been able to determine key signatures $(n=44,100 \%)$. The majority of participants have been able to determine the time signature $(n=39,88.63 \%)$. The majority of participants have also been able to determine the lowest and highest tones $(n=36,81.81 \%)$. In the fourth aspect, more than half of the participants were able to determine the tone interval $(n=25,56.81 \%)$. However, this number was not satisfactory because there were still quite a lot of participants who answered incorrectly in determining the interval of the tones $(n=19,43.19 \%)$. This raised the question, "Why, after being able to determine key signatures, time signatures, and melody ranges, are the participants still unable to determine the tone interval correctly?" Upon further investigation, it was identified that the majority of the participants determined the tone interval by looking at (drawing) the piano keys then calculated them, and others determine the interval of the tone with an estimate without looking at the piano key picture. The participants who saw the piano images can determine the tone interval more accurately.

To see the development of the participants' song notation reading skill, they were tested to read songs notations directly and individually. They were given a series of song notations in the number of four bars in meters 4/4 (20 beats) and were given a value of one point for each beat, so the total was 20 points. In other words, participants got a value of 20 if they could read the notation correctly in each beat and in a fixed tempo, whether the tempo was slow or fast. The types of notes used were varied, including $1 / 2,1 / 4,1 / 8$, and $1 / 16$ notes. The reading test results are depicted in Figure 1. 


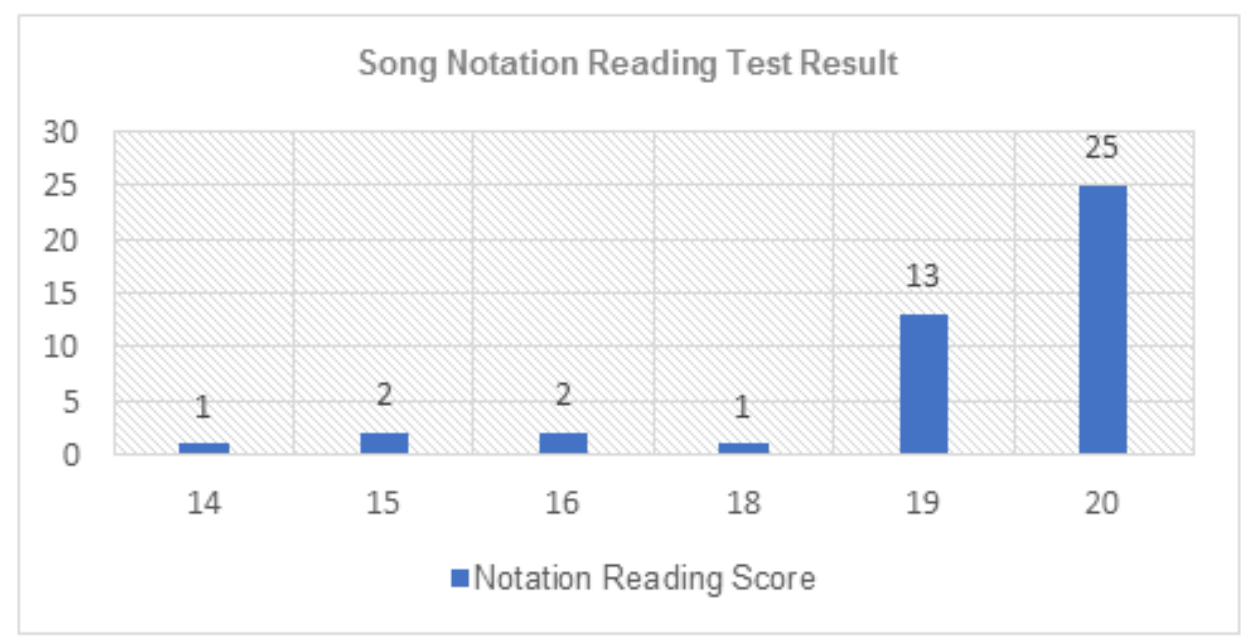

Figure 1. Song notation reading test score

Figure 1 depicts that out of 44 participants (100\%), 25 (56.82\%) participants were able to read all parts of song notation correctly, $13(29.55 \%)$ participants were able to read 19 parts of song notation correctly, 1 (2.27\%) participant was able to read 18 parts of the notation correctly, two (4.55\%) participants were able to read 16 parts of song notation correctly, two $(4.55 \%)$ participants were able to read 15 parts of song notation correctly, and 1 (2.27\%) participant was able to read 14 parts of song notation correctly. There was no participant who could not read song notations in less than 14 parts.

\section{Discussion and Conclusions}

The test results of analyzing and reading song notations from pre-action and post-action were compared. The comparison results showed that these participants' comprehension and skills had been improved. In the pre-action test, the participants were unable to determine key signatures, time signatures, melody ranges, and tone intervals. They did not know the consequences of how to read or determine the values of notes when the time signatures change. They also did not understand that the solmization position can change when the key signature changes, so that the interval tone analysis was also incorrect. Furthermore, the post-action test showed that the problems had decreased in most participants. It was evident that, out of $44(100 \%)$ participants, no one answered incorrectly in determining the key signature. Only five (11.37\%) participants answered incorrectly in determining the time signature. Eight (18.19\%) participants who answered incorrectly in determining the melody range of songs did so because they were not careful in seeing sharp marks on song notation even though it was the initial benchmark for identifying solmization positions. Then, 19 $(43.19 \%)$ participants who answered incorrectly in determining the pitch interval did so because they relied on their memories to calculate pitch distance even though they had not really memorized the notes, while other participants relied on piano images in doing the analysis so they could answer correctly. The picture of the piano as a medium was an important factor for participants to understand the tone interval. In line with other studies, media must consciously be used in education (Kartal, 2018) and teachers must have media literacy competencies media (Simons, Meeus, \& T'Sas, 2017).

The results of a comparison between the song notation reading tests also showed that the participants had shown an significant improvement in their song notation reading skill. Most participants have been able to read song notations correctly. As for some reading errors experienced by a small number of participants, they were focused on two problems, namely errors in reading a series of $1 / 16$ note and $1 / 2$ note. The participants read the $1 / 16$ note incorrectly when combined with the $1 / 8$ note. Their reading was too fast and some were too slow. Meanwhile, an error in reading the $1 / 2$ note (two taps) was made by the participant who read it as one tap and as three taps. In this case, the participants need intense training to sound a rhythmic pattern in various types of notes because, in essence, continuous intense training is a major factor in improving musical skills (Ericsson, 1998, 2006; Ericsson \& Lehmann, 1996; Hayes, 2013; Sosniak, 1985). The participants also needed to train their focus on the number of beats when reading. They said the melody together with their hands tapping. However, when it happened, sometimes the number of beats was out of sync with the value of notes that must be read. This condition also shows that the participants' musical sensitivity also needed to be honed.

One aspect that is difficult to change in the participants was the accuracy of their vocal pitch. Their skill in reading song notation was improved, but their vocal pitch did not necessarily improve. This was because the potential to develop vocal pitch was only effective during childhood 
(Flowers \& Dunne-Sousa, 1990; Leighton \& Lamont, 2006). However, some participants enjoyed reading song notations using the piano application $(n=25,56.81 \%)$, and some preferred reading notations using their own vocals even though their voices were inadequate $(n=19,43.19 \%)$. On another note, a participant who liked reading song notations using their own vocals said, "If I can use my own vocals well, then the use of the instrument will be smooth. So, it is easier to start using my own vocals." In addition, there was also a participant who said, "By using my own vocals, I can estimate the notes." Meanwhile, students who preferred to read song notations with the piano application said, "By using a musical instrument, the tone will be more precise than my vocals." Another participant expressed, "The use of musical instruments will directly sound the notation correctly. If using my vocals means that I have to synchronize the sounds of the tone and the solmization, then I think that is quite difficult for me."

Following that, a survey was conducted to see the extent to which the participant beliefs improved after going through the action steps. The survey results showed that 41 (93.2\%) participants claimed to have been able to understand and describe a song notation, 40 (90.9\%) participants claimed to have understood the terms listed in song notations, $41(93.2 \%)$ participants claimed to have known the note values in a song notation, $44(100 \%)$ participants claimed to have known the tonality of a song notation, and $43(97.7 \%)$ participants claimed to have been able to read song notations. This data shows that the participants were confident that they have understood song notations and have the ability to read them. This belief is important for participants to bring their self-confidence as a prospective music teacher, and self-confidence in teaching music can be improved through mastery teaching experiences (de Vries, 2013).

In conclusion, a series of action research processes have answered the research questions. Why are prospective elementary school teachers unable to read song notations? The survey results showed that they were not used to reading notations in the form of note symbols; they did not understand the consequences of changes in time signatures and key signatures, and they also did not understand how to read rhythmic patterns in various types of notes. During their school years, they were accustomed to reading number notations without using music staff. Do prospective elementary school teachers know the importance of song notation reading comprehension and skill? The survey results showed that they knew that song notation can make it easier for teachers to learn and teach songs, but that knowledge was not balanced with efforts to improve their song notation reading skill. Do prospective elementary school teachers know how to improve their song notation reading comprehension and skill? They have only been following music lessons as given in schools, and all these lessons did not necessarily give them knowledge on how to improve their song notation reading comprehension and skill both individually and in groups. Can a series of action steps about how to read song notation improve the understanding and skills of prospective elementary school teachers? The results of this action research showed that, through a series of critical-reflective units, song notation reading comprehension and skill from the majority of the prospective elementary school teachers can be improved, so that their music literacy is improved as well. In other words, the issue of poor song notation reading comprehension and skills could be addressed by implementing critical-reflective actions steps through collaboration works between related parties

\section{Suggestions}

The research found that the 12 years of formal schooling in Indonesia was unable to make students literate in music notations. When they enter the elementary school teacher education program, the problem that they constantly face is the inability to learn and teach songs by reading notation. Therefore, as a suggestion, Indonesia needs to improve the teaching system of prospective primary school music teachers by opening elementary school art (music, dance and fine art) teacher education programs.

\section{Acknowledgement}

An utmost gratitude is extended to the Research and Community Service Institution (LPPM - Lembaga Penelitian dan Pengabdian pada Masyarakat) and the Primary School Teacher Education Program of Indonesia University of Education that have facilitated and funded this research.

\section{REFERENCES}

[1] Bamberger, J. S. (1995). The mind behind the musical ear: How children develop musical intelligence: Harvard University Press.

[2] Bozkuş, K., \& Bayrak, C. (2019). The Application of Dynamic Teacher Professional Development Approach through Experimental Action Research. International Electronic Journal of Elementary Education (4), 335-352\% V 311.

[3] Brigham, T. J. (2014). Taking Advantage of Google's Web-Based Applications and Services. Medical Reference Services Quarterly, 33(2), 202-210. doi:10.1080/02763869 .2014.897521.

[4] Bruce, C. D., Flynn, T., \& Stagg-Peterson, S. (2011). Examining what we mean by collaboration in collaborative action research: a cross-case analysis. Educational Action Research, 19(4), 433-452. doi:10.1080/09650792.2011.625 667. 
[5] Burton, S. L. (2017). Making music mine: The development of rhythmic literacy. Music education research, 19(2), 133-142.

[6] Chiu, C.-H., Cheng, H.-W., \& Wu, C.-Y. (2016). Applying questioning or reading strategy to review technology enhanced coedited notes of elementary school students. The Journal of Educational Research, 109(2), 111-121. doi:10.1080/00220671.2014.924471.

[7] Cook, N. (1990). Music, imagination, and culture: Oxford University Press.

[8] Creswell, J. W. (2015). Educational Research: Planning, Conducting, and Evaluating Quantitative and Qualitative Research, Enhanced Pearson eText with Loose-Leaf Version--Access Card Package. United Kingdom: Pearson Education, Inc.

[9] de Vries, P. (2013). Generalist teachers' self-efficacy in primary school music teaching. Music education research, 15(4), 375-391. doi:10.1080/14613808.2013.829427

[10] Edwards-Groves, C., \& Kemmis, S. (2016). Pedagogy, Education and Praxis: understanding new forms of intersubjectivity through action research and practice theory. Educational Action Research, 24(1), 77-96.doi:10.1080/09 650792.2015.1076730.

[11] Elkoshi, R. (2007). The effects of in-school stave notation learning on student's symbolising behaviour and musical perception. Music education research, 9(3), 355-371.

[12] Elliott, D. J. (1995). Music Matters: A New Philosophy of Music Education. New York: Oxford University Press.

[13] Ericsson, K. A. (1998). The scientific study of expert levels of performance: General implications for optimal learning and creativity. High Ability Studies, 9(1), 75-100.

[14] Ericsson, K. A. (2006). The influence of experience and deliberate practice on the development of superior expert performance. The Cambridge handbook of expertise and expert performance, 38, 685-705.

[15] Ericsson, K. A., \& Lehmann, A. C. (1996). Expert and exceptional performance: Evidence of maximal adaptation to task constraints. Annual review of psychology, 47(1), 273-305.

[16] Fasanaro, A., Spitaleri, D., Valiani, R., \& Grossi, D. (1990). Dissociation in musical reading: A musician affected by alexia without agraphia. Music Perception: An Interdisciplinary Journal, 7(3), 259-272.

[17] Ferguson-Patrick, K. (2007). Writers develop skills through collaboration: an action research approach. Educational Action Research, 15(2), 159-180. doi:10.1080/0965079070 1314585.

[18] Flowers, P. J., \& Dunne-Sousa, D. (1990). Pitch-pattern accuracy, tonality, and vocal range in preschool children's singing. Journal of Research in Music Education, 38(2), 102-114.

[19] Greenwood, D. J., \& Levin, M. (2006). Introduction to action research: Social research for social change: SAGE publications.

[20] Gudmundsdottir, H. (2007). Error analysis of young piano students' music reading performances. Paper presented at the 8th Conference of the Society for Music Perception and Cognition, Concordia University, Montreal.

[21] Gudmundsdottir, H. R. (2010). Advances in music-reading research. Music education research, 12(4), 331-338.

[22] Hargreaves, D. J. (1992). The developmental psychology of music. New York: University of Cambridge Press.

[23] Hayes, J. R. (2013). The complete problem solver: Routledge.

[24] Heil, D. (2005). The internet and student research: Teaching critical evaluation skills. Teacher Librarian, 33(2), 26.

[25] Hermanson, L. W. (1972). An investigation of the effects of timbre on simultaneous vocal pitch acuity of young children. (Doctoral dissertation), Columbia University, New York. $(323,3558 \mathrm{~A})$.

[26] Hultberg, C. (2007). Psychological tools in music. Paper presented at the 5th International Conference for Research in Music Education, School of Education and Lifelong Learning, University of Exeter, 10-14 April.

[27] Ilomaki, L. (2007). Conceptions of music literacy in aural training: findings from an action research project. Paper presented at the 5th International Conference for Research in Music Education, School of Education and Lifelong Learning, University of Exeter, 10-14 April.

[28] Jaipal, K., \& Figg, C. (2011). Collaborative action research approaches promoting professional development for elementary school teachers. Educational Action Research, 19(1), 59-72. doi:10.1080/09650792.2011.547688.

[29] Julia, J., Hakim, A., \& Fadlilah, A. (2019). Shifting Primary School Teachers Understanding of Songs Teaching Methods: An Action Research Study in Indonesia. International Journal of Education and Practice, 7(3), 158-167. doi: http://dx.doi.org/10.18488/journal.61.2019.7 3.158.167.

[30] Kartal, O. Y. (2018). Investigating the Effectiveness of Media Research on Noticing Media Effects: A Multiple Case Study. World Journal of Education, 8(4), 159-169.

[31] Kemmis, S., \& McTaggart, R. (2005). Participatory Action Research: Communicative Action and the Public Sphere. In N. K. Denzin \& Y. S. Lincoln (Eds.), The SAGE handbook of qualitative research (3rd ed) (pp. 556-604). Thousand Oaks, CA: Sage.

[32] Kemmis, S., McTaggart, R., \& Nixon, R. (2014). The action research planner: Doing critical participatory action research: Springer Science \& Business Media.

[33] Kopiez, R., Weihs, C., Ligges, U., \& Lee, J. I. (2006). Classification of high and low achievers in a music sight-reading task. Psychology of Music, 34(1), 5-26.

[34] Lee, W. C., Gu, H. Y., Chung, K. L., Lin, C. Y., Fahn, C. S., Lai, Y. S., . Hsu, M. K. (2011). The development of a music reading and singing two-wheeled robot. Journal of the Chinese Institute of Engineers, 33(4), 531-539. doi:10.1080/02533839.2010.9671641.

[35] Leeman, Y., van Koeven, E., \& Schaafsma, F. (2018). Inter-professional collaboration in action research. Educational Action Research, 26(1), 9-24.doi:10.1080/096 50792.2017.1301827. 
[36] Leighton, G., \& Lamont, A. (2006). Exploring children's singing development: do experiences in early schooling help or hinder? Music education research, 8(3), 311-330. doi:10.1080/14613800600957461.

[37] Lin, Y.-T., Chang, C.-H., Hou, H.-T., \& Wu, K.-C. (2016). Exploring the effects of employing Google Docs in collaborative concept mapping on achievement, concept representation, and attitudes. Interactive Learning Environments, 24(7), 1552-1573. doi:10.1080/10494820.2 015.1041398 .

[38] Long, M. (2007). Rhythm based music intervention: evidence of cognitive transfer to literacy skills. Paper presented at the 5th International Conference for Research in Music Education, School of Education and Lifelong Learning, University of Exeter, 10-14 April.

[39] McTaggart, R. (1994). Participatory action research: Issues in theory and practice. Educational Action Research, 2(3), 313-337.

[40] McTaggart, R. (1996). Issues for participatory action researchers. In O. Zuber-Skerritt (Ed.), New directions in action research (pp. 203-213). USA: Taylor \& Francis.

[41] Palmer, C., \& Krumhansl, C. L. (1987). Pitch and temporal contributions to musical phrase perception: Effects of harmony, performance timing, and familiarity. Perception \& Psychophysics, 41(6), 505-518.

[42] Penttinen, M., Huovinen, E., \& Ylitalo, A.-K. (2015). Reading ahead: Adult music students' eye movements in temporally controlled performances of a children's song. International Journal of Music Education, 33(1), 36-50. doi: $10.1177 / 0255761413515813$.

[43] Persellin, D., Smith, L., Klein, M., \& Taguiam, E. (2002). An investigation of the effects of vocal modeling on the development of singing ability in kindergarten children. Texas Music Education Research, 20(1), 2-10.

[44] Persellin, D. C. (2006). The effects of vocal modeling, musical aptitude, and home environment on pitch accuracy of young children. Bulletin of the Council for Research in Music Education, 39-50.

[45] Puurtinen, M. (2018). Learning on the Job: Rethinks and Realizations about Eye Tracking in Music-Reading Studies. Frontline Learning Research, 6(3), 148-161.

[46] Rusinek, G. (2007). Investigating good practice in secondary music education: a culturally embedded. Paper presented at the 5th International Conference for Research in Music Education, School of Education and Lifelong Learning, University of Exeter, 10-14 April.

[47] Schön, D., \& Besson, M. (2002). Processing pitch and duration in music reading: A RT-ERP study. Neuropsychologia, 40(7), 868-878.

[48] Simons, M., Meeus, W., \& T'Sas, J. (2017). Measuring Media Literacy for Media Education: Development of a Questionnaire for Teachers' Competencies. Journal of Media Literacy Education, 9(1), 99-115.

[49] Sims, W. L., Moore, R. S., \& Kuhn, T. L. (1982). Effects of female and male vocal stimuli, tonal pattern length, and age on vocal pitch-matching abilities of young children from England and the United States. Psychology of Music.
[50] Sloboda, J. A. (1976). The effect of item position on the likelihood of identification by inference in prose reading and music reading. Canadian Journal of Psychology/Revue canadienne de psychologie, 30(4), 228.

[51] Sloboda, J. A. (1978). The psychology of music reading. Psychology of Music, 6(2), 3-20.

[52] Sloboda, J. A. (1984). Experimental studies of music reading: A review. Music Perception: An Interdisciplinary Journal, 2(2), 222-236.

[53] Somekh, B. (2010). The Collaborative Action Research Network: 30 years of agency in developing educational action research. Educational Action Research, 18(1), 103-121. doi:10.1080/09650790903484566

[54] Somekh, B., \& Zeichner, K. (2009). Action research for educational reform: remodelling action research theories and practices in local contexts. Educational Action Research, 17(1), 5-21. doi:10.1080/09650790802667402

[55] Sosniak, L. A. (1985). Learning to be a concert pianist. Developing talent in young people, 1, 19-67.

[56] Supriyadi, T., \& Julia, J. (2019). The Problem of Students in Reading the Quran: A Reflective-Critical Treatment through Action Research. International Journal of Instruction, 12(1), 311-326.

[57] Travis, L. (2010). One of Many Free Survey Tools: Google Docs. Journal of Electronic Resources in Medical Libraries, 7(2), 105-114. doi:10.1080/15424065.2010.482902

[58] Waters, A. J., \& Underwood, G. (1999). Processing pitch and temporal structures in music reading: Independent or interactive processing mechanisms? European Journal of Cognitive Psychology, 11(4), 531-553.

[59] Wolf, T. (1976). A cognitive model of musical sight-reading. Journal of psycholinguistic research, 5(2), 143-171.

[60] Yarbrough, C., Green, G., Benson, W., \& Bowers, J. (1991). Inaccurate singers: An exploratory study of variables affecting pitch-matching. Bulletin of the Council for Research in Music Education, 23-34.

[61] Zuber-Skerritt, O. (2018). An educational framework for participatory action learning and action research (PALAR). Educational Action Research, 26(4), 513-532.doi:10.1080/ 09650792.2018.1464939 